\title{
REELABORAÇÕES DA DITADURA CHILENA NA NARRATIVA DE UM HOMOSSEXUAL: TENGO MIEDO TORERO, DE PEDRO LEMEBEL ${ }^{1}$
}

\section{REVELATIONS OF THE CHILD'S DICTATORSHIP IN THE NARRATIVE OF A HOMOSSEXUAL: TENGO MIEDO TORERO BY PEDRO LEMEBEL}

\author{
José Veranildo Lopes da Costa Junior ${ }^{2}$ \\ [http://orcid.org/0000-0002-2400-8715] \\ DOI: 10.30612/raido.v14i35.11256
}

\begin{abstract}
RESUMO: Pode-se dizer que a literatura latino-americana contemporânea é caracterizada por uma constante reelaboraçăo do passado e da história oficial que nos contam. Nesse sentido, um traço importante do projeto literário de Pedro Lemebel é a reconstruçáo dos anos de ditadura militar chilena. Nosso artigo apresenta uma leitura do romance Tengo miedo torero, publicado por Pedro Lemebel, em 2001 [2002], com o objetivo de perceber como o referido autor narra o período de autoritarismo no Chile.
\end{abstract}

Palavras-chave: Literatura chilena; Ditadura; Pedro Lemebel.

ABSTRACT: Contemporary Latin American Literature is characterized by the constant reworking of the past and the official history that we are told. Pedro Lemebel's Literary Project is based on the reconstruction of the years of Chilean Military Dictatorship. This way, this article presents a reading of the novel "Tengo Miedo Torrero", published by Pedro Lemebel in 2001 [2002], in order to understand how the author narrates the period of authoritarianism in Chile.

Keywords: Chilean literature; Dictatorship; Pedro Lemebel.

1 Este artigo é um recorte da nossa tese de doutorado intitulada "Homossexualidade e autoritarismo: uma leitura de Herbert Daniel, Osvaldo Bazán e Pedro Lemebel", defendida junto ao Programa de PósGraduaçāo em Letras da Universidade do Estado do Rio Grande do Norte (PPGL/UERN).

2 Professor Adjunto do Departamento de Letras Estrangeiras da Universidade do Estado do Rio Grande do Norte (DLE/UERN). E-mail: jveranildo@hotmail.com 


\title{
INTRODUÇÃO
}

\author{
Miedo, tengo miedo \\ miedo de quererte \\ Miedo, tengo miedo \\ Miedo de perderte \\ Sueño noche y día \\ Que sin ti me quedo \\ Tengo, vida mía, ¿miedo? \\ ¡ay, mucho miedo!
}

A epígrafe que abre nosso texto é um excerto da cançăo Tengo miedo torero, interpretada pela artista espanhola Sara Montiel, cujo título nomeia o único romance escrito por Pedro Lemebel. A narrativa em questăo foi publicada em 2001 [2002] e, segundo uma nota que introduz o romance, "este libro surge de veinte páginas escritas a fines de los 80, y que permanecieron por ańos traspapeladas entre abanicos, medias de encaje y cosméticos que mancharon de rouge la caligrafía romancera de sus letras" (LEMEBEL, 2002, p. 06). Com essa observaçâo, Lemebel parece aproximar o leitor do seu universo gay, no qual a literatura entra em contato com objetos de maquiagem, ao longo dos anos 1980, ressaltando, dessa forma, a sua vivência homossexual e transgressora.

Além de escritor e artista plástico, Pedro Lemebel se destacou também pela sua atuaçấo como performer, tendo participado do coletivo de artes Yeguas del Apocalipsis, no qual desenvolveu inúmeras performances que, dentre outros temas, questionavam o autoritarismo, a violência de gênero, o capitalismo e a sociedade burguesa chilena. Wanderlan Alves (2012, p. 182) observa que "el nombre del grupo es claramente una parodia a los Caballeros del Apocalipsis, pero, más allá de ello, constituye una afirmación crítica de las categorías de género en la sociedad chilena de la época". Segundo o pesquisador, a palavra "yegua" refere-se, popularmente, no Chile, ao homossexual afeminado, ou seja, aos homens gays que performan traços da feminilidade em seus corpos, o que justifica, inclusive, a nota introdutória do romance, cujas primeiras vinte páginas encontravam-se manchadas de maquiagem.

A temática principal da narrativa de Pedro Lemebel, incluindo as diversas crônicas publicadas, as fotografias e as performances, é o autoritarismo chileno e os seus desdobramentos na vida cotidiana de pessoas "comuns". Desse modo, nâo podemos dissociar a produçâo artística de Pedro Lemebel da sua militância em torno da defesa das minorias sociais, da democracia e dos direitos humanos.

Sendo assim, percebe-se que o projeto literário do referido escritor chileno é atravessado por fatos que contam a história do Chile e narram a própria vida de Lemebel. 0 autor cria um jogo que localiza Tengo miedo torero nos limites incertos da realidade e da ficçăo, ao dedicar a obra a alguns personagens reais, dentre eles "a la vieja del almacén, copuchenta como ella sola, pero una tumba a la hora de las preguntas" (LEMEBEL, 2002, p. 06) e "también, a la casa, donde revolotearon eléctricas utopías en la noche púrpura de aquel tiempo" (LEMEBEL, 2002, p. 06). A velha do armazém e a casa, respectivamente, sâo descritos na narrativa e podem representar uma aproximaçăo da vida de Pedro Lemebel, através de pessoas conhecidas e fatos vivenciados (ALVES, 2012).

Laura Janina Hosiasson, em Tengo miedo torero, de Pedro Lemebel: Pasodoble e melodrama (2018, p. 01), relembra que a referida narrativa "se inscreve numa tradiçấo de romances sobre a ditadura chilena, já a esta altura bastante volumosa". Para a 
professora, parte da produçăo literária chilena, a partir de 11 de setembro de 1973, encontra-se marcada pela ficcionalizaçáo da ditadura na literatura (HOSIASSON, 2018). Nesse sentido, parece que existe, de fato, um projeto de construçăo da identidade nacional chilena que perpassa a ficçăo e a produçăo artística do país.

Focando na narrativa chilena, Tocornal Orostegui (2007) afirma que o projeto de Pedro Lemebel abarca as duas fases da ditadura implantada pelos militares naquele país. A primeira fase corresponde à etapa Terrorista, que começa com o golpe de 1973 e problematiza a perseguiçấo aos cidadâos chilenos como uma estratégia de medo e de submissăo ao regime autoritário. A segunda diz respeito à etapa Constitucional da ditadura chilena, desenvolvida entre os anos 1980 e 1988, quando acontece um plebiscito e o Chile inicia o seu processo de transiçáo democrática. Esta etapa é recorrente na América Latina e, em síntese, tange a tentativa de tornar constitucionalmente aceito o golpe ao Estado democrático. ${ }^{3}$

Tengo miedo torero localiza-se temporalmente no ano 1986, quando houve um atentado contra o ditador chileno, durante o regime autoritário. $O$ enredo é construído em torno da história da Loca del Frente, uma personagem conhecida como a bicha louca que escuta tangos, boleros e rancheiras antigas. Tem-se a seguir a descriçâo inicial da personagem:

Todo el barrio sabía que el nuevo vecino era así, una novia de la cuadra demasiado encantada con esa ruidosa construcción. Un maripozuelo de cejas fruncidas que llegó preguntando si se arrendara ese escombro terremoteado de la esquina. Esa bambalina sujeta únicamente por el arribismo urbano de tiempos mejores. Tantos años cerrada, tan llena de ratones, ánimas y murciélagos que la loca desalojó implacable, plumero en mano, escoba en mano rajando las telarañas con su energía de marica falsete entonando a Lucho Gatica, tosiendo el "bésame mucho" en las nubes de polvo y cachureos que arrumaba en la cuneta (LEMEBEL, 2002, p. 08).

A chegada de uma travesti dramática que transformava a sua vida em um verdadeiro bolero catastrófico chamava a atençăo dos moradores do bairro. Marca-se a oposiçăo entre masculino e feminino, através de palavras como "vizinho" e "a louca", como qualificadores do corpo híbrido da personagem, uma travesti, isto é, "representante de una categoría híbrida sin lugar determinado" (ALVES, 2012, p. 188). Hosiasson (2018) também observa que o narrador de Tengo miedo torero, utilizando-se de boleros, tangos e outros ritmos, cria uma escrita em diálogo com uma tradiçâo de autores latino-americanos, como Lezama, Arenas e Puig, que se aproximam de uma sensibilidade proscrita que possibilita um movimento performático na literatura.

Sobre a Loca del frente, lembramos que a personagem de Pedro Lemebel é nascida e criada na favela chilena (HOSIASSON, 2018). Trata-se de um "homossexual velho e patético, em aposentadoria compulsiva, quase careca e com a dentadura postiça que nem sempre lembra de colocar" (HOSIASSON, 2018, p. 03) e tem um gosto cafona por enfeites, plumas e danças. Outra característica da narrativa de Pedro Lemebel reside no fato de que esse escritor criou, no seu projeto literário, diversos personagens

3 Um exemplo advém do Brasil e das inúmeras tentativas de setores conservadores de tornar constitucionalmente aceito o processo de natureza sexista, misógina e machista de golpe presidencial de Dilma Rousseff. 
oriundos das classes menos favorecidas, o que ilustra o seu compromisso com o tecido social minoritário.

Outrossim, a Loca del frente é uma personagem particular. Ainda que as ruas de Santiago estivessem ocupadas por protestos políticos e que a principal rádio noticiasse as ameaças de Pinochet e os ataques à populaçăo, por exemplo, "ella no estaba ni ahí con la contingencia política" (LEMEBEL, 2002, p. 09). As velhas da rua, em tom de fofoca, ironizavam que "solamente le falta el novio" (LEMEBEL, 2002, p. 08) e, ante uma indiferença política, a referida personagem levava a sua vida como se a normalidade do cotidiano náo houvesse sido afetada pelo regime ditatorial. O narrador do romance crítica:

Más bien le daba susto escuchar esa radio que daba puras malas noticias. Esa radio que se oía en todas partes con sus canciones de protesta y ese tararán de emergencia que tenía a todo el mundo con el alma en un hilo. Ella prefería sintonizar los programas del recuerdo: “Al compás del corazón". "Para los que fueron lolos". “Noches de arrabal". Y así se lo pasaba tardes enteras bordando esos enormes manteles y sábanas para alguna vieja aristocrática que le pagaba bien el arácnido oficio de sus manos (LEMEBEL, 2002, p. 10).

Tendo em vista o desinteresse inicial da Loca del frente com a conjuntura política do seu país, durante a narrativa, a protagonista vai, gradativamente, envolvendo-se com política, talvez por influência do personagem Carlos ou simplesmente porque "poco a poco se da cuenta de que es víctima constante de distintas formas y niveles de opresión; por su clase social, por su divergencia ideológica y aun por su (homo)sexualidad" (ALVES, 2012, p. 195). A respeito da violência de cunho social vivida por essa personagem, Alves (2012) também comenta que Tengo miedo torero problematiza os processos falidos de modernizaçâo que provocaram uma densa estratificaçâo social, sob a qual a citada personagem é uma das vítimas. Desse modo, é necessário, ademais, ressaltar que a narrativa de Pedro Lemebel, de forma recorrente, colocou em pauta a ampla segregaçâo social resultante do golpe de Estado operado no Chile.

Além disso, a história do romance se encadeia a partir do momento em que a Loca del frente se envolve com Carlos, um jovem heterossexual que militava contra a ditadura de Pinochet. Eles se conheceram no Armazém da rua, quando ele pedia ajuda para guardar umas caixas que continham livros, mas na verdade eram armas:

Esas cajas tan pesadas, que mandó a guardar ese joven que conoció en el almacén, aquel muchacho tan buenmozo que le pidió el favor. Diciendo que eran solamente libros, pura literatura prohibida, le dijo con esa boca de azucena mojada. Con ese timbre tan macho que no pudo negarse y el eco de esa boca siguió sonando en su cabecita de pájara oxigenada. Para qué averiguar más entonces, si dijo que se llamaba Carlos no sé cuanto, estudiaba no sé qué, en no sé cuál universidad, y le mostró un carnet tan rápido que ella ni miró, cautivada por el tinte violáceo de esos ojos (LEMEBEL, 2002, p. 10).

A partir daí a Loca del frente se apaixona por Carlos, considerado um belo guerrilheiro, com atuaçáo política contrária ao regime autoritário de Pinochet. A travesti que, até entăo năo tinha nenhum interesse por política, decide se inserir nas atividades da militância, na tentativa de conquistar e viver uma história de amor com Carlos. Por sua vez, Alves (2012) constata que a narrativa de Pedro Lemebel relaciona as questóes de 
gênero e sexualidade à dimensăo política e em consonância com as estruturas sociais da sociedade chilena. De acordo com o pesquisador mencionado:

Su literatura parece articular, en cierto modo, la reivindicación del amor como conquista de alguna realización individual aun en contextos en que la subjetividad están sometidas a la violencia y al autoritarismo. En alguna manera es como si el amor convirtiera la sexualidad en principio o deseo de vida (Marcuse, 1968). El amor surge en su obra vinculado con el deseo, que promueve la acción (homo) sexual, política, intelectual, etc., a la vez que le aporta un sentido de manifestación en contra del carácter normativo y patriarcal (Arboleda-Ríos, 2011) de la sociedad chilena bajo la dictadura de Pinochet (ALVES, 2012, p. 186).

Desse modo, parte da chave de leitura da narrativa de Pedro Lemebel consiste compreender que as relaçóes firmadas no romance em questăo, ressaltam a dimensâo política dos arranjos afetivos homossexuais e do sexo como açáo refutadora que, ao desestabilizar os binarismos de gênero operante, săo capazes de validar outra forma de se relacionar com o mundo, para além daquela proposta por uma matriz de base heterossexual, ou seja, "la sexualidad puede convertirse en un mecanismo de poder que se vincula con las más diversas formas de acción en el tejido social" (ALVES, 2012, p. 187).

Segundo Alves (2012), Tengo miedo torero apresenta três visōes da história do Chile. A primeira é a conservadora, que advoga que os militares, preocupados com a pátria, a família, o capital e todos os valores tradicionais, planejavam perpetuar-se no poder. Trata-se de uma parcela da sociedade que acreditava no discurso de que os militares iriam resolver a crise social-econômica e, instantaneamente, convocariam eleiçóes democráticas. A segunda perspectiva corresponde aos revolucionários da época que, organizados em grupos de esquerda e classificados como marxistas, questionaram a legitimidade do governo militar no Chile. Por último, temos a reflexăo sobre o passado que, através de textos literários, por exemplo, reconstrói o período autoritário chileno.

Considerando esse debate, enfatizamos que o romance de Pedro Lemebel, ao entrelaçar vida pessoal e história do Chile, transforma elementos como o sexo, a homossexualidade e a militância em temas centrais para que seja possível reelaborar os anos de golpe de Estado no Chile. Além disso, o projeto artístico do conhecido escritor chileno é enviesado por atos performáticos, os quais sâo adjetivados como performances de resistência e de questionamento de práticas autoritárias, segregadoras e excludentes. Nesse artigo, buscaremos apresentar uma leitura sobre a literatura de resistência escrita por um gay afeminado durante os anos de autoritarismo chileno, com vistas a compreender os mecanismos de reelaboraçăo do golpe de Estado citados anteriormente.

\section{FICÇÃO, HISTÓRIA E GOLPE MILITAR}

A narrativa de vida de Pedro Lemebel confunde-se com a própria história do Chile. Em nossa opiniăo, Lemebel năo pode ser visto exclusivamente como um artista que enfrentou os militares. Seu engajamento político transformou-o em uma verdadeira fonte de informaçăo sobre a ditadura vivida em seu próprio país. Por consequência, năo é difícil encontrar inúmeras referências ao período de autoritarismo nas páginas 
do romance Tengo miedo torero. O primeiro parágrafo da narrativa citada ocupa-se de localizar temporalmente a história narrada durante a primavera dos anos 1986. De acordo com a memória do narrador:

COMO DESCORRER UNA GASA sobre el pasado, una cortina quemada flotando por la ventana abierta de aquella casa la primavera del 86. Un año marcado a fuego de neumáticos humeando en las calles de Santiago comprimido por el patrullaje. Un Santiago que venía despertando al caceroleo y los relámpagos del apagón; por la cadena suelta al aire, a los cables, al chispazo eléctrico. Entonces la oscuridad completa, las luces de un camión blindado, el párate ahí mierda, los disparos y las carreras del terror, como castańuelas de metal que trizaban las noches del fieltro. Esas noches fúnebres, engalanadas de gritos, del incansable "Y va a caer", y de tantos, tantos comunicados de último minuto, susurrados por el eco radial del "Diario de Cooperativa" (LEMEBEL, 2002, p. 07).

As recordaçóes do narrador ocorrem a partir do espaço da sua casa, localizada na capital chilena, quando as ruas da cidade estavam cobertas por uma cortina de fumaça, causada pelos pneus queimados em resposta ao golpe militar em vigor. O terror e o trauma imposto pelos militares qualificam as noites do ano 1986 como fúnebres, ressaltando o fato de que, durante este período de autoritarismo, a morte foi um dos principais mecanismos de controle e de censura aos sujeitos que lutavam contra os militares.

Além disso, o romance de Lemebel apresenta algumas referências ao Diário da Cooperativa, um dos jornais do país que mantinha uma posiçâo contrária ao regime, denunciando as perseguiçóes, a tortura e a morte dos cidadăos. A narrativa é também formada por algumas notas do respectivo jornal, as quais funcionam como comunicados à naçăo sobre o cotidiano da vida ao longo do golpe militar. Um desses informes diz: "COOPERATIVA ESTÁ LLAMADO: VIOLENTOS INCIDENTES Y BARRICADAS SE REGISTRAN EN ESTE MOMENTO EN LA ALAMEDA BERNARDO O'HIGGINS" (LEMEBEL, 2002, p. 13) assim, podemos perceber que, a referida rádio se comunicava com o povo chileno a partir de um discurso de objetividade (ARAVENA, 2008), o qual buscava informar sobre os principais ataques políticos, como uma estratégia de resistência e de informaçăo.

Segundo Morales (2009), a ditadura no Chile foi implantada a partir da consumaçâo de dois objetivos centrais. O primeiro diz respeito à derrubada presidencial de Allende, quando os militares ocuparam o poder por quase 17 anos de autoritarismo. $O$ segundo objetivo encontra-se alinhado a imposiçáo de um novo modelo econômico em vigor no Chile: ou seja, o neoliberalismo. Ainda, de acordo com o estudioso, a imposiçâo ditatorial e econômica foi construída a partir da vinculaçăo de um discurso popular através da programaçăo televisiva. Desse modo, se parte da televisăo chilena ajudou a fortalecer um discurso massivo e popular a favor dos militares e das reformas neoliberais, a rádio Cooperativa atuava como um meio de oposiçâo ao regime militar (ARAVENA, 2008). A seguir, recuperamos outro informe da Rádio Cooperativa:

COOPERATIVA, LA RADIO DE LA MAYORÍA. MANOLA ROBLES INFORMA: UN COMUNICADO DEL MINISTERIO DEL INTERIOR SEŃALA QUE, EN EL ALLANAMIENTO EFECTUADO HOY POR SERVICIOS DE SEGURIDAD EN VARIAS POBLACIONES, SE HAN INCAUTADO ARMAS DE PESADO CALIBRE Y NUMEROSO MATERIAL IMPRESO LLAMANDO A LA REBELIÓN, PERTENCIENTE AL LLAMAO FRENTE PATRIÓTICO MANUEL RODRÍGUEZ (LEMEBEL, 2002, P. 37). 
Chama atençâo a adjetivaçâo "rádio da Maioria", pois, decorre daí o fato de que este meio de comunicaçăo tornou-se uma forma de resistência ao autoritarismo chileno já que, "Cooperativa, en efecto, se había instalado en el imaginario colectivo como la radio de todos los chilenos" (ARAVENA, 2008, p. 80), o que evidencia o caráter popular e a recepçăo positiva da rádio no tecido social, principalmente o da classe operária. Outrossim, as notas informativas da rádio produziram efeitos de realidade, permitindo que a sociedade chilena pudesse construir uma memória coletiva sob os ataques dos militares ao Estado democrático de direito (ARAVENA, 2008), os quais podem ser percebidos em comunicaçóes como:

\title{
SERGIO CAMPOS DA LECTURA A LAS NOTICIAS: EL AUTODENOMINADO FRENTE PATRIÓTICO MANUEL RODRÍGUEZ SE ADJUDICÓ EL CORTE DE ENERGÍA QUE DEJÓ SIN LUZ A LA REGIÓN METROPOLITINA (LEMEBEL, 2002, P. 27).
}

Náo se trata apenas do anúncio de que a regiăo metropolitana de Santiago encontrava-se sem energia elétrica. Pelo contrário, o comunicado de que o entorno da capital estava sem luz produz um efeito de realidade o qual, por sua vez, parece funcionar como uma metáfora para a escuridáo vivida no Chile em razăo do golpe de Estado. Pelo carácter político, a Rádio Cooperativa, inúmeras vezes, teve sua programaçâo censurada pelos militares: "En tal nirvana hitleriano, los noticieros de radio y televisión estaban prohibidos, y más aún esa radio Cooperativa y su tararán marxista que tenía revolucionados a los flojos de este país" (LEMEBEL, 2002, p. 20), pois entendia-se que a Rádio, assim como outros meios de comunicaçăo que se opuseram ao regime, eram formados por marxistas que queriam derrubar os militares.

Em consonância com as mensagens objetivas transmitidas pela Rádio, o romance Tengo miedo torero, ao criar uma memória coletiva a partir dos efeitos de realidade produzidos, ambienta a capital Santiago com as seguintes palavras:

\begin{abstract}
LA PRIMAVERA HABÍA LLEGADO A SANTIAGO como todos los años, pero ésta se venía con vibrantes colores chorreando los muros de grafitis violentos, consignas libertarias, movilizaciones sindicales y marchas estudiantiles dispersas a puro guanaco. A todo peńascazo los cabros de la universidad resistían el chorro mugriento de los pacos. Y una y otra vez volvían a la carga tomándose la calle con su ternura Molotov inflamada de rabia. A bombazo limpio cortaban la luz y todo el mundo comprando velas, acaparando velas y más velas para encender las casas y cunetas, para regar de brasas la memoria, para trizar de chispas el olvido. Como si bajaran la cola de un cometa rozando la tierra en homenaje a tanto desaparecido (LEMEBEL, 2002, p. 19).
\end{abstract}

O relato do narrador mostra que, aparentemente, a vida pública seguia o fluxo da normalidade. Como todos os anos, a primavera coloria as ruas de Santiago com cores e flores, entretanto, neste ano, a ditadura havia se instalado no país. As ruas estavam ocupadas pelos movimentos sociais, pelos sindicatos e pelos estudantes. A populaçáo, por sua vez, acendia velas porque náo havia energia. Com esta descriçăo, se constrói a imagem da capital Santiago, uma metrópole iluminada pelas velas que mais pareciam homenagens aos desaparecidos políticos.

Desse modo, recordamos que Lemebel tinha apenas 18 anos quando se instalou o golpe militar de 1973. Ou seja, o escritor vivenciou a ditadura durante a sua juventude, 
diferentemente de outros intelectuais que contam o trauma a partir da história ou da memória do outro, por năo terem vivido diretamente este momento histórico. Nas palavras de Morales (2009, p. 225), o jovem escritor "vivió los años de la dictadura en Chile, es decir, la experiencia de una vida cotidiana sometida a la vigilancia, la excusión, la censura, el miedo". Por esta linha de pensamento, justifica-se a aproximaçâo entre o romance e a história do Chile, pois nos parece que Pedro Lemebel optou por escrever uma literatura comprometida com a memória coletiva, com a denúncia ao autoritarismo, sendo estas estratégias de um compromisso de memória (RICEUR, 2007) com o passado, mas também com o futuro das novas geraçōes.

Passado, presente e futuro se bifurcam na construçăo da narrativa, de modo que, nessa reelaboraçáo do passado, as mulheres possuem um papel fundamental na cobrança por justiça e por memória. Semelhante ao caso das măes da Praça de Maio, na Argentina, em que mulheres se reúnem semanalmente para cobrar que o Estado esclareça o desaparecimento político de seus filhos e netos, Tengo miedo torero também conta a história das măes da Praça de Armas:

\begin{abstract}
Malditos asesinos, pensó, pero ya van a ver cuándo Carlos y sus amigos del Frente les vuelen la raja de un bombazo. La vida es muy justa y ya les va a tocar a ellos, siguió pensando al pararse y caminar cojeando hasta la Plaza de Armas, donde esperó encontrar tranquilidad ese día de mierda. Pero, al llegar cerca de la Catedral, un numeroso grupo de mujeres se juntaban en las escaleras portando las fotos de sus familiares detenidos desaparecidos. JUSTICIA - QUEREMOS - JUSTICIA. LOS LLEVARON - DETENIDOS - NO - LOS - VIMOS - NUNCA - MÁS. LO - QUE - AHORA - EXIGIMOS - QUE -NOS - DIGAN - DÓNDE - ESTABAN. Eran las consignas que coreaban las señoras, abuelas, hermanas de toda esa gente que aparecía desteńida en las fotos clavadas en el pecho (LEMEBEL, 2002, p 164).
\end{abstract}

As mulheres se reuniam nas proximidades da Catedral de Santiago com fotos dos seus parentes desaparecidos, semelhante ao movimento que ocorre semanalmente em Buenos Aires. Gritavam por justiça e exigiam explicaçóes do Estado para o desaparecimento dos seus entes. Nota-se a resistência dessas mulheres que, mesmo vivendo sob um Estado de exceçăo, ocuparam as ruas da capital para protestar contra os militares, cobrar justiça e memória, a partir do trauma vivido após perceberem que os seus parentes eram desaparecidos políticos.

A partir dessas descriçôes cria-se a imagem de uma Santiago cinzenta, com pneus queimando nas ruas, ocupadas pelos movimentos sociais, durante o início dos 17 anos de ditadura que devastaram a democracia no Chile. Săo, portanto, descriçôes de uma metrópole arruinada pela ditadura, cujas imagens săo produzidas por um grupo particular no tecido social chileno: o de homens gays e proletários que, ao denunciar os militares, cobravam do Estado respeito para com as sexualidades năo-hegemônicas e os direitos humanos de homossexuais e travestis.

\title{
2 CONCLUSÕES
}

Este artigo apresentou uma leitura do único romance escrito por Pedro Lemebel, Tengo miedo torero (2001) [2002], tentando perceber os mecanismos de reelaboraçâo da ditadura chilena operados por uma militante homossexual que coloca em cena uma personagem protagonista travesti, caracterizada pela performatividade de suas açóes. 
De modo geral, a imagem reelaborada pela narrativa de Lemebel em torno da ditadura naquele país apresenta uma Santiago destroçada por bombas, pneus queimados e muita repressáo militar. Formam-se, ainda, duas imagens: a de jovens que lutam em defesa da democracia em contraponto a apatia de um conjunto de cidadáos que acreditam que há uma espécie de normalidade cotidiana mesmo quando as vidas săo permanentemente vigiadas pelo aparelho de opressâo do Estado.

A partir da análise da referida obra, avaliamos que o texto de Pedro Lemebel, ao trazer para a ficçâo contemporânea uma reelaboraçáo dos anos de autoritarismo chileno assume, concomitantemente, a defesa da democracia e das liberdades individuais. Trata-se, portanto, de um romance em que o desejo por democracia pulsa em cada palavra escrita pelo referido autor. 


\section{REFERÊNCIAS}

ALVES, W. Fronteras del deseo: melodrama y crítica social en Tengo miedo torero, de Pedro Lemebel. Castilla: Estudios de Literatura. Valladolid, v. 3, n. 1, pp. 181-204, 2012.

ARAVENA, C. A. R. La verdad está en los hechos: una tensión entre objetividad y oposición: Radio Cooperativa en dictadura. Historia. Santiago, v. 1, n. 41, pp. 79-98, 2008.

HOSIASSON, L. J. Tengo miedo torero, de Pedro Lemebel: Pasodoble e melodrama. ResearchGate, 2018.

LEMEBEL, P. Tengo miedo torero. Sexta edición. Santiago: Seix Barral, 2002.

MORALES, L. Pedro Lemebel: género y sociedade. Aisthesis. Santiago, v. 1, n. 46, pp. 222-235, 2009.

OROSTEGUI, C. T. Una mirada a "la loca" de Pedro Lemebel: de figura privilegiada a figura paradigmática. 2008. 81 f. Dissertaçâo (Mestrado em Literatura Chilena) - Universidad de Chile, Santiago, 2007.

RICEUR, P. A memória, a história e o esquecimento. Campinas: Editora da Unicamp, 2007. 